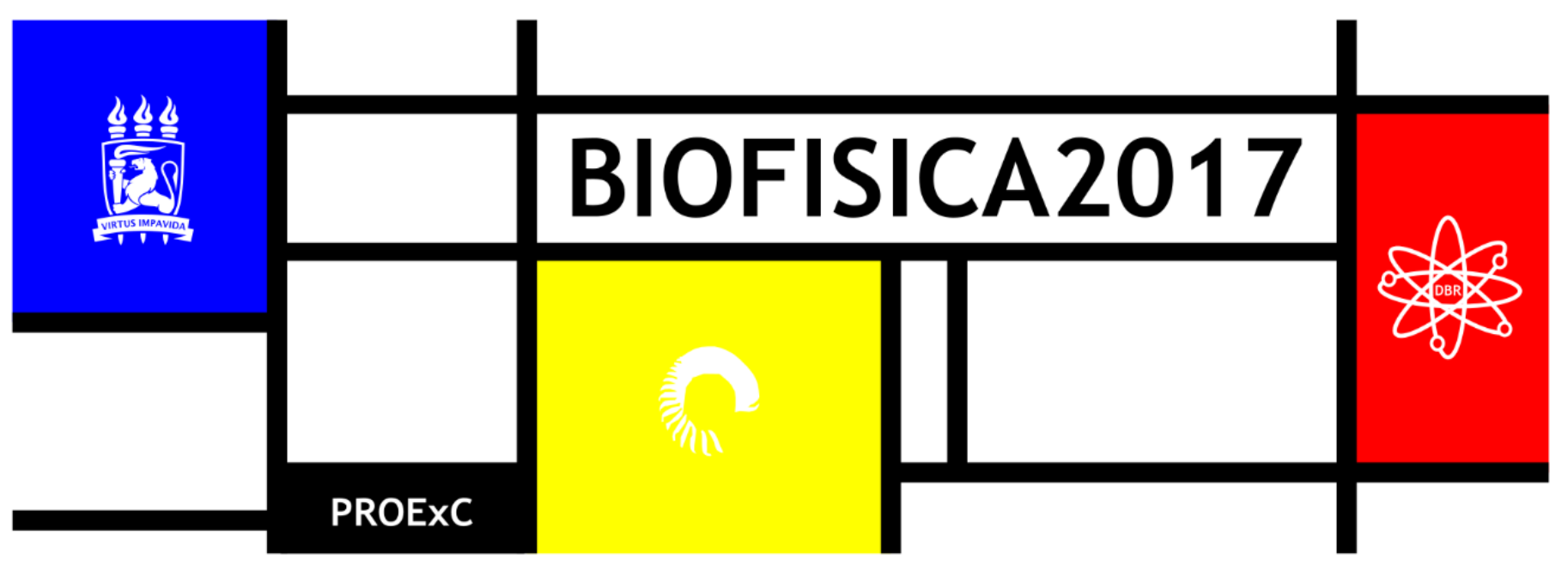

\title{
ANÁLISE ECOTOXICOLOGICA E MUTAGÊNICA DA REGIÃO TÊXTIL DE TORITAMA UTILIZANDO Daphnia magna e Biomphalaria glabrata
}

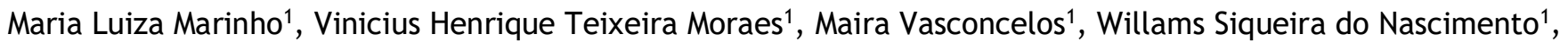 \\ Danielle Xavier Serapião², Ana Maria Mendonça de Albuquerque Melo ${ }^{1}$
}

${ }^{1}$ Departamento de Biofísica e Radiobiologia Universidade Federal de Pernambuco-UFPE, Agência Estadual de Meio Ambiente CPRH ${ }^{2}$ *mluizamarinho@gmail.com

\section{INTRODUÇÃO}

A intensa liberação de substâncias químicas no meio ambiente tem causado inúmeros problemas aos seres vivos e um dos primeiros organismos a serem afetados por essas substâncias são os organismos presentes nos ecossistemas aquáticos. Os ecossistemas aquáticos são utilizados como um dos principais locais de despejo de diferentes tipos de dejetos e resíduos produzidos pelo homem, como lançamento de resíduos industriais e domésticos (DE ANDRADE, 2013). Conforme Espindola et al. (2000), a contaminação dos ecossistemas aquáticos que, uma vez despejados no ambiente, interagem de acordo com suas características e com as condições do meio receptor, sendo sujeitos a transformações químicas (hidrólises), físicas (fotólises) e biológicas (decomposição) podendo atingir níveis mais altos da cadeia trófica por meio da bioacumulação. A água é um dos recursos naturais mais importantes do planeta. As principais fontes de água potável são lagos e rios, que constituem apenas $0.3 \%$ da água doce no mundo. Esse recurso natural é fundamental para toda comunidade, pois ela é necessária para suprir as necessidades alimentares, de saúde e nos processos produtivos industriais (BAIRD; CANN, 2011).

Dentre estes processos industriais causadores de danos ao meio ambiente, merece destaque o setor têxtil que é considerado um dos segmentos industriais mais poluidores de águas superficiais. Seus processos são responsáveis por consumir elevada quantidade de água, que posteriormente é convertida em efluentes ricos em compostos nocivos ao meio ambiente. (CHEN et al., 2011; PALÁCIO, 2012).

O setor têxtil de Pernambuco é considerado um dos polos economicamente mais importante no estado. A concentração das empresas do setor de confecções encontra-se nos municípios de Caruaru, Santa Cruz do Capibaribe, Surubim e Toritama (SANTOS 2012). Durante o processamento têxtil, aproximadamente $20 \%$ da carga de corantes é liberada como resíduos de tingimento nos ecossistemas aquáticos (SILVA 2012). Por serem altamente coloridos, devido à presença de corantes que não se fixaram durante o processo de tingimento, os resíduos têxteis podem ser liberados sem o devido tratamento, interferindo na absorção da luz, provocando modificações nas atividades fotossintetizantes da biota nos corpos d'água, provocando a morte da flora e fauna aquáticas (SILVA, 2012; CHEN et al., 2011). Além desse fato, estudos indicam que algumas classes de corantes e seus subprodutos podem ser carcinogênicos e/ou mutagênicos; podem conter surfactantes, compostos orgânicos e inorgânicos, sais, óleos e graxas. As análises ecotoxicológicas têm por finalidade saber em qual grandeza as substâncias químicas, isoladas ou em misturas, são nocivas ao meio ambiente e como e onde se manifestam seus efeitos (KNIE \& LOPES 2004). É através da toxicologia que se pode avaliar a contaminação ambiental em diversas fontes poluidoras, tais como: efluentes agrícolas, industriais, domésticos, sedimentos, medicamentos e produtos químicos em geral, estimando o grau de impacto que podem causar nos rios, lados e oceanos (AREZON; NETO, 2011). A toxicologia é um metodo empregado no monitoramento de efluentes industriais com o intuito de minimizar seus impactos e também como requisito para a obtenção e manutenção de licenças junto aos órgãos ambientais (PIMENTEL, et al 2009).

\section{MATERIAIS E MÉTODOS}

Foram realizadas coletas das águas do Rio Capibaribe na cidade de Toritama em três pontos diferentes: montante, jusante e um Ponto Aleatório em relação às lavanderias têxteis. Para os testes foram utilizados neonatos do microcrustáceo Daphnia magna de até $24 \mathrm{~h}$ de idade expostos às três amostras em diluições: $100 \%, 50 \%, 25 \%$, $12,5 \%, 6,25 \%, 3,125 \%, 1,56 \%$ e $0,78 \%$. Após introduzir os 10 neonatos jovens em cada recipiente de teste, incluindo o controle, o ensaio foi coberto filme de PVC com mantido na estufa incubadora em temperatura de $20^{\circ} \mathrm{C} \pm 2{ }^{\circ} \mathrm{C}$ por 48 horas em bandejas com os béqueres de $50 \mathrm{~mL}$ identificados com cada diluição e amostra. $O$ efeito tóxico foi dado através da capacidade natatória dos organismos e mortalidade a partir de uma contagem realizada no final do experimento. A expressão dos resultados foi dada se observada imobilidade maior que $10 \%$ nos organismos. Também foram utilizados moluscos da espécie Biomphalaria glabrata para testar sua sensibilidade frente a amostras ambientais. Utilizou-se para o bioensaio 80 moluscos adultos com diâmetro de concha entre 12 a $14 \mathrm{~mm}$ observados durante cinco 
dias consecutivos. Em seguida 60 moluscos sexualmente maduros foram separados para serem utilizados nos experimentos. Os testes de toxicidade aguda com moluscos adultos consistem na exposição do organismo por um período de 48 horas a amostras. Após a exposição os moluscos foram analisados quanto ao comportamento, características morfológicas e mutagenicidade. 0 procedimento utilizado para preparação das lâminas no teste é feito para verificação de possíveis alterações celulares, como presença de micronúcleo, apoptose celular, grânulos celulares e binucleações. Metodolodia estabelecida por Silva, 2013. Para cada individuo foi coletado $100 \mu \mathrm{L}$ de hemolinfa e colocado em lâminas microscópicas, em seguida foi depositado sobre a mesma quantidade de ácido etilenodiaminotetracético (EDTA) misturado com Ringer numa concentração final de $10 \mathrm{mM}$.

Após esse procedimento, cada lâmina foi colocada por 30 minutos em câmara úmida. Passado este tempo, as células foram fixadas com $200 \mu \mathrm{L}$ gluteraldeído a $1 \%$ em solução de Ringer, por 5 minutos. Para corar as lâminas, foi utilizada uma solução estoque de Giemsa (Merck), Azur- eosina-azul de metileno, diluída em tampão fosfato, pH 6.8, obtendo uma solução final a $5 \%$. As lâminas foram submersas nesta solução por 7 minutos e em seguida lavadas com água destilada e posteriormente submetidas à secagem em temperatura ambiente para serem analisadas no microscópio óptico (Medilux).

\section{RESULTADO E DISCUSSÃO}

Os estudos ecotoxicológicos são fundamentais para avaliar e compreender a extensão de determinados impactos ocasionados pela contaminação da água. Esses estudos possibilitam a criação de legislações e geram informações para os setores responsáveis pela saúde pública e pelo ambiente, auxiliando estes na criação de políticas ambientais (BARROS e DAVINO, 2003; BRIGANTE e ESPÍNDOLA, 2003, APUD FLYNN, 2015). Nesses estudos ecotoxicológicos, a literatura recomenda que sejam utilizados mais de um organismo-teste para as amostras coletadas, pois a resposta de uma substância-teste sob o metabolismo de um único tipo de organismo bioindicador pode diferir de outro, principalmente quando os componentes das amostras analisadas são desconhecidos (ARAGÃO \& ARAÚJO, 2006). O microcrustáceo de água doce, Daphnia magna tem sido amplamente utilizado como indicador biológico em estudos e controle da qualidade da água e em testes de toxicidade na avaliação de efluentes (NIETO, 2000, LAITANO, 2003). De acordo com Espindola (2000), as Daphnias são excelentes bioindicadores de efluentes industriais, principalmente de efluentes têxteis. A daphnia mostrou toxicidade para uma amostra analisada no presente trabalho. Houve $100 \%$ de mortes dos neonatos da amostra da jusante até a $16^{\text {a }}$ diluição, onde havia $6,25 \%$ da amostra e $93,75 \%$ de meio de cultivo. Esse resultado confirma 0 alto grau de sensibilidade das daphnias frente a amostras ambientais.

Tabela 1: Resultado da toxicidade da água do Rio sobre $D$. magna mostrando os pontos de coleta.

\begin{tabular}{ccccc}
\hline \multicolumn{5}{c}{ Pontos de coleta } \\
\hline Diluição & $\begin{array}{l}\text { Concentração } \\
(\%)\end{array}$ & J & M & P.A \\
\hline $1: 1$ & 100 & + & - & - \\
$1: 2$ & 50 & + & - & - \\
$1: 4$ & 25 & + & - & - \\
$1: 8$ & 12,5 & + & - & - \\
$1: 16$ & 6,25 & + & - & - \\
$1: 32$ & 3,125 & - & - & - \\
$1: 64$ & 1,56 & - & - & - \\
$1: 128$ & 0,78 & - & - & - \\
Fator de Toxicidade & Ft> & Ft=1 & Ft=1 \\
\hline
\end{tabular}

0 molusco respondeu positivamente aos ensaios mostrando toxicidade diante das amostras ambientais, que foi expressa através dos danos celulares (Apoptose celular, granulações e binucleações) observados em todos os pontos analisados (Jusante, Montante e Ponto Aleatório).

O gráfico A mostra as apoptoses celulares que ocorrerem na exposição dos moluscos adultos após $48 \mathrm{~h}$, para os pontos da Montante, Jusante e Ponto aleatório. Houve diferença significativa $(P<0.05)$ em todos os pontos analisados em comparação ao grupo controle, com destaque para o número de apoptoses celulares encontradas na amostra da jusante que foi muito superior aos demais. Apoptose celular é um fenômeno biológico genético que representa a morte celular, que pode ser causada por fatores externos, tóxicos, imunológicos e infecciosos (ANDRADE, 2011). Essas apoptoses celulares se apresentam como características de defesa do molusco e mostram que houve tentativa de sanar os danos celulares após as exposições ambientais, evidenciando a toxicidade da amostra. No controle não foram encontrados dados significativos.

A

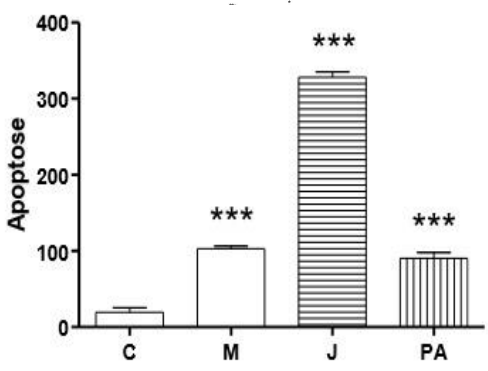

Figura 1: Apoptoses celulares encontradas nos hemócitos após a exposição de 48h.

Essas células fazem parte de uma categoria juntamente com os hialinócitos na hemolinfa. Sabe-se que os granulócitos são os responsáveis pela fagocitose de partículas estranhas e o número destas células bem como a taxa de fagocitose aumentam consideravelmente após exposição a determinado agente tóxico (SERRANO et al., 2002). O resultado obtido nessa análise, onde o $P$ $<0.05$ mostra que as granulações encontradas foram significativas principalmente na Montante e na Jusante. No Ponto Aleatório os danos observados não foram significativos, bem como no controle.

B

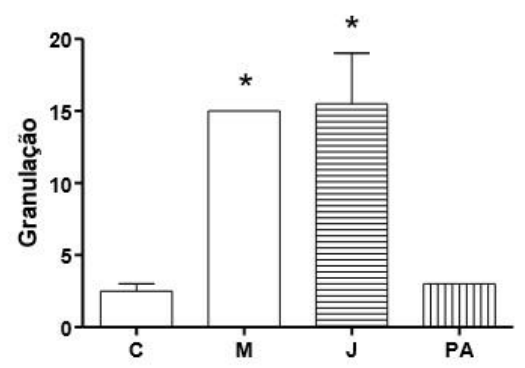

Figura 2. 0 número de granulócitos observados nos três pontos analisados, porém em maior número nos pontos da Jusante e Montante.

Células binucleadas são células com a presença de dois núcleos e um citoplasma maior em comparação com as células normais. Estas células são um indicativo de que o houve falha durante citocinese e isso pode estar relacionado com um atraso da divisão celular e exposição a poluentes tóxicos a poluentes tóxicos ambientais, confirmando o seu potencial para biomonitoramento ambiental (CARRARD, 2007; BOLOGNESI, 2012). 


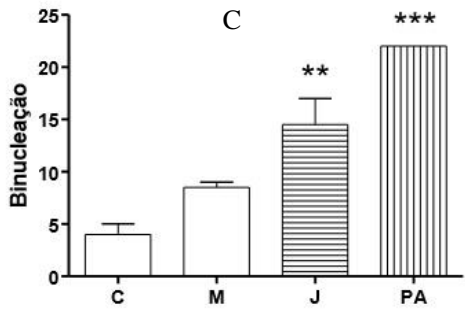

Figura 3. Binucleações encontradas após a exposição, para os pontos da Montante, Jusante e Ponto aleatório, bem como do controle.

\section{CONCLUSÕES}

De acordo com a literatura estudada, os testes de toxicidade com Daphnia magna são testes bastante reconhecidos internacionalmente como modelos ideais para bioensaios de qualidade ambiental. Os moluscos da espécie Biomphalaria glabrata também têm se mostrado um modelo experimental bastante aceitável, pois as mutações genéticas nos hemocitos são detectáveis após diversas exposições (KAWANO, 1992; MUNZINGER, 1987). A sensibilidade do molusco diante do material analisado corrobora com bioindicadores de amostras ambientais conhecidos na literatura. Além disso, B. glabrata possui outras características que o enquadram como um organismo ideal de monirotamento ambiental: ciclo de vida conhecido, fácil manutenção, baixo custo laboratorial, facil manuseio e testes com resultados rápidos. Os resultados obtidos expressam a sensibilidade do $B$. glabrata frente a amostras.

É de grande importância pesquisas que promovam a descoberta de novos organismos que possam ser utilizados como bioindicadores ambientais. 0 monitoramento ambiental fornece informações essenciais sobre a extensão dos poluentes e seus prováveis impactos. É através desses estudos que avaliamos as ações mitigadoras, adotadas com a intenção de diminuir e eliminar sua origem, por isso são fundamentais para a avaliação do grau de degradação ambiental. É de extrema importância destacar a utilização de ensaios realizados em conjuntos (ecotoxicidade e mutagenicidade) uma vez que são capazes de gerar respostas em diferentes níveis complementares, permitindo a melhor compreensão do efeito da substância em questão e tornando a avaliação da qualidade da água mais segura (CHAPMAN, 1989).

\section{REFERENCIAS}

DE ANDRADE JR et al. “Ajustes hematológicos em tambaqui (Colossoma macropomum curvier, 1818) exposto a diferentes concentrações de chorume." Revista Colombiana de Ciencia Animal, v. 5, n. 1, p. 71-82, 2013.

ESPINDOLA, E. L. et al. Ecotoxicologia : pespectiva para o secelo XXI. São Carlos. SP.Ed Rima, p. 757, 2000.

BAIRD, C.; CANN, M. Química Ambiental. 4. ed. Porto Alegre: Bookman, 2011.

CHEN, B.; XIKUI, W.; CHEN, W.; WENGIANG, J.; SHUPING, L. Degradation of azo dye direct sky blue $5 \mathrm{~B}$ by sonication combined with zero-valent iron. Ultrasonics Sonochemistry, v.18, p.1091-1096, 2011.
PALÁCIO, S. M. et al. "Estudo da toxicidade de efluente têxtil tratado por foto-fenton artificial utilizando as espécies lactuca sativa e artemia salina." ENGEVISTA 14.22012.

SANTOS, V. L., SILVA, P. D. S., SILVA, R., \& ALBUQUERQUE, E. C. "Avaliação do processo fenton solar no tratamento de efluente gerado por lavanderia de jeans de Pernambuco." In Embrapa Semiárido-Artigo em anais de congresso (ALICE). In: CONGRESSO BRASILEIRO DE ENGENHARIA QUÍMICA, 19, Búzios. Anais... São Paulo: Associação Brasileira de Engenharia Química, 2012.

KNIE, Joachim L W; LOPES, Ester W B. Testes ecotoxicológicos: métodos, técnicas e aplicações. 20. E dFlorianópolis: Gráfica Coan, 2005.

ARENZON, Alexandre; NETO, Tiago José Pereira; GERBER, Wagner. "Manual sobre toxicidade em efluentes industriais". Cespe/Senai de Artes Gráficas Henrique D'ávila Bertaso, Porto Alegre, 2011.

PIMENTEL, M. F.; LIMA, D. P. DE; MARTINS, L. R.; BEATRIZ, A.; SANTAELLA, S. T.; LOTUFO, L. V. C. Ecotoxicological analysis of caschew nut effluents, specifically two of its major phenolics components, cardol and cardanol. Pan American Journal of Aquatic Sciences, [S.l], v. 4, n. 3, p. 363-368, 2009.

SILVA, L. R. S.; Avaliação da radiossensibilidade de hemócitos de Biomphalaria glabrata expostos à radiação gama, Scientia Plena, v.9, p. 16, 2013.

BARROS, S.B.M. \& DAVINO, S.C. In: Fundamentos de toxicologia. Avaliação da toxicidade. São Paulo, v.2, p.57-68. 2003.

BRIGANTE, J. \& ESPÍNDOLA, E.L.G. In: Limnologia fluvial. O estudo no rio MogiGuaçu: a abordagem metodológica. São Paulo, v.1, p.15-22. 2003.

ARAGÃO, M. A. e ARAÚJO, R.P.A. Métodos de Ensaios de Toxicidade com Organismos Aquáticos. Cap. 6, p: 117 - 152. 2006.

ZAGATO, P.A. e BERTOLETTI, E. Ecotoxicologia aquática - princípios e aplicações. ZAGATTO e BERTOLETTI (org.) São Carlos: Rima; 2006.

FLYNN, Maurea Nicoletti et al. Avaliação de toxicidade em sedimentos do rio Juqueri (SP) com Vibrio fischeri e Hyalella azteca. Revinter Revista de Toxicologia, Risco Ambiental e Sociedade, v. 2, n. 2, 2015.

ARAGÃO, M. A. \& ARAúJO, R. P. A., 2006, Métodos de Ensaios de Toxicidade com Organismos Aquáticos. In: ZAGATTO, P. A. \& Bertoletti, E. Ecotoxicologia Aquática - Princípios e Aplicações. São Carlos, São Paulo, p. 117-152. 2006.

LAITANO, KS. Testes de toxicidade com Daphnia magna: uma ferramenta para avaliação de um reator experimental UASB. Dissertação de Mestrado. Universidade Federal de Santa Catarina. Florianópolis, Brasil. 85p. 2003. NIETO, Regis. "Caracterizaçâo ecotoxicológica de efeluentes líquidos industriais-ferramenta para ações de controle da poluiçâo das âguas." Congreso Interamericano de Ingeniería Sanitaria y Ambiental, 27. ABES, 2000.

ANDRADE, Sonia G. Apoptose e sua importância no curso da infecção pelo Trypanosoma cruzi. Revista de Patologia Tropical, v. 32, n. 2, p. 163-174, 2011. 